\title{
UJIAN TEORI PENERIMAAN SISWA BARU DI SMK BHAKTI LOA JANAN BERBASIS INTRANET
}

\author{
Awang H. Kridalaksana ${ }^{1)}$, Kusno Harianto ${ }^{2)}$, Hadi Wiyarno ${ }^{3)}$ \\ ${ }^{1,2,3}$ Teknik Informatika, STMIK Widya Cipta Dharma \\ $1,2,3$ Jl. Prof. M. Yamin No. 25, Samarinda, 75123 \\ E-mail : awangkid@gmail.com ${ }^{1)}$, kusnoharianto97.kh@gmail.com ${ }^{2}$, h4d1_029@yahoo.co.id ${ }^{3)}$
}

\begin{abstract}
ABSTRAK
Maksud dan tujuan dari penelitian ini yakni untuk mengetahui kendala dalam pelaksanaan ujian teori Penerimaan Siswa Baru, dengan memanfaatkan media interaktif berbasis web, sehingga pemanfaatan teknologi berbasis web dapat menjadi solusi sebagai media interaktif sekarang ini.

Untuk mencapai tujuan tersebut, alat bantu yang digunakan antara lain Flowchart dan SiteMap (Peta Situs), serta Spesifikasi Kebutuhan Sistem perangkat lunak yang digunakan antara lain menggunakan Database MySQL, Web Developer menggunakan PHP, Editor dan Web Design, dan Image Processing menggunakan Adobe Photoshop. Adapun metode pengumpulan data menggunakan studi lapangan yang terdiri dari pengamatan langsung (observasi) dan wawancara serta studi pustaka.

Dari hasil implementasi sistem, bahwa dengan penggunaan website ini dapat membantu dalam pelaksanaan ujian teori penerimaan siswa baru dari ujian konvensional menjadi ujian online oleh calon siswa baru. Sehingga input data peserta, koreksi soal, rekap nilai semua sudah terkomputerisasi yang ditampilkan berbasis Intranet yang cukup dinamis.
\end{abstract}

Kata Kunci: Ujian Teori, Intranet

\section{PENDAHULUAN}

Di zaman sekarang ini perkembangan teknologi meningkat pesat di berbagai bidang, terutama perkembangan teknologi komputer, baik perkembangan pada perangkat lunak maupun perangkat keras. Di negara-negara maju hampir semua bidang menerapkan sistem komputerisasi, karena dengan sistem komputerisasi dapat mencapai kemudahan kerja yang tinggi sehingga kualitas dan kuantitas dari hasil pekerjaan lebih baik dari pada menggunakan sistem yang belum terkomputerisasikan.

Terutama sekolah-sekolah SMK seperti di SMK Bhakti Loa Janan Kabupaten Kutai Kartanegara, setelah membuka pendaftaran penerimaan siswa baru maka harus dilakukan seleksi sesuai ketentuan sekolah dan petunjuk dari dinas pendidikan setempat. Dalam melakukan seleksi siswa baru ini yang disebut ujian konvensional memerlukan administrasi yang banyak seperti absensi peserta, soal dan lembar jawaban kerja peserta ujian untuk masing-masing calon siswa baru dan setelah itu mengoreksi dan merekap nilai. Dalam melakukan hal ini cukup memakan waktu yang cukup lama jika calon siswa berjumlah banyak.

Permasalahan yang timbul bagi panitia penerimaan siswa baru (PSB) dan staf Tata Usaha seperti pendataan calon siswa, pembuatan soal, lembar jawaban, laporan hasil ujian konvensional seleksi penerimaan siswa baru yang akan diumumkan dalam waktu dekat. Selain itu faktor kecurangan dan menyontek banyak terjadi pada proses ujian konvensional serta penghematan biaya dalam proses pembuatan soal seperti biaya kertas dan tintah dapat diminimalisir.

Dengan penggunaan ujian teori penerimaan siswa baru berbasis intranet ini maka kesalahan pencatatan, kejemuan dalam pengoreksian serta perhitungan, dan keakuratan data untuk nilai hasil ujian dapat dipertanggungjawabkan, selain itu pelaporan hasil ujian seleksi akan dengan mudah dan cepat dalam penyajiannya.

Dalam hal lain adanya ujian seleksi teori penerimaan siswa baru berbasis intranet ini juga diharapkan dapat memperbaiki sistem yang telah berjalan dan dapat membuat pekerjaan panitia dan staf Tata Usaha (TU) menjadi lebih efektif, efisien dalam melakukan pendataan calon siswa dan pelaksanaan seleksi calon siswa barudan tidak kalah pentingnya mengurangi biaya yang dikeluarkan oleh pihak sekolah.

Dengan tersedianya aplikasi ujian online di SMK Bhakti Loa Janan ini diharapkan dapat membantu guru menyelenggarakan ujian online yang sehat, serta efektif dan efisien. Dengan alasan tersebut penulis memilih judul "Ujian Teori Penerimaan Siswa Baru di SMK Bhakti Loa Janan Berbasis Intranet".. 


\section{RUANG LINGKUP PENELITIAN \\ 2.1 Rumusan Masalah}

Adapun persoalan yang dihadapi dalam kasus ini adalah sebagai berikut: "Bagaimana membuat ujian online ini dengan interface yang sederhana sehingga mudah dioperasikan oleh calon siswa baru SMK Bhakti Loa Janan”.

\subsection{Batasan Masalah}

Dalam skripsi ini tidak menjelaskan secara keseluruhan yang ada pada ujian teori Penerimaan Siswa Baru (PSB) berbasis intranet, akan tetapi hanya sebagian saja yang akan dibahas. Ada pun yang akan dibahas dalam penulisan ini adalah:

1) Aplikasi dibuat dengan menggunakan bahasa pemrograman PHP dan MySql sebagai database.

2) Proses ujian yang diperuntukan bagi calon siswa baru SMK Bhakti Loa Janan.

3) Aksesnya hanya bisa dilakukan di jaringan lokal (intranet) SMK Bhakti Loa Janan.

4) Guru yang membuat soal sudah termasuk panitia yang melakukan input soal.

5) Soal ujian bertipe pilihan ganda (multiple choice) dengan 5 pilihan.

6) Jumlah soal yang ditampilkan dalam aplikasi ini sebanyak 40 soal.

7) Soal ujian online ditampilkan secara acak (random) pada setiap komputer client dan ujian dilakukan tidak serentak. Dilaksanakan dengan beberapa gelombang, satu gelombang sebanyak 40 peserta.

8) Peserta atau user sudah mendaftar sebagai calon siswa baru di SMK Bhakti Loa Janan.

9) Peserta atau user yang sudah melakukan ujian tidak bisa mengikuti ujian lagi dan nilai tidak ditampilkan langsung.

\subsection{Tujuan}

Dalam pembuatan ini ditentukan beberapa tujuan pembuatan sistem ini,diantaranya:

1) Memudahkan proses ujian yang biasanya dilakukan secara konvensional.

2) Berupaya mencoba memberikan sesuatu yang berbeda untuk pelaksanaan ujian calon siswa baru di SMK Bhakti Loa Janan dengan mengubah sistem ujian konvensional ke sistem ujian online.

3) Berupaya untuk mempermudah penyelenggaraan ujian karena Ujian online sudah tidak lagi menggunakan media kertas atau alat tulis sebagai media ujian. Sistem ujian ini dibangun secara komputerisasi, dimana peserta ujian langsung mendapat dan menjawab soal ujian melalui komputer.

\section{BAHAN DAN METODE}

\subsection{Penjelasan Bahan}

Untuk mendukung dalam penganalisaan hasil penelitian diperlukan suatu konsep dalam merumuskan definisi-definisi yang menunjang kegiatan penelitian baik teori dasar maupun teori umum. Ini akan dijelaskan tentang tinjauan dari peneliti sebelumnya yang membahas ujian Penerimaan Siswa Baru pada sekolah dan teori-teori pendukung yang berhubungan dengan permasalahan yang dibahas.

1) Kajian Empiris

Ditinjau dari peneliti sebelumnya yang juga membahas tentang Membangun Software Ujian Masuk Sekolah Menengah Umum untuk siswa baru ditulis oleh Yayat (2010) berbasis desktop, Jurnal Teknomatika Sistem Ujian Berbasis Web oleh Bobby Melky Tulangow (2011), dan Analisis dan Perancangan Sistem Ujian Online Pada Pelajaran TIK di Sekolah Menengah Pertama 1 Tawangmangu oleh Asih Parwati.

2) Kajian Teoritis

Dalam menghadapi permasalahan yang ada, sangat penting untuk mengetahui teori-teori yang berhubungan dengan permasalahan yang akan dihadapi. Semua teori tersebut dapat digunakan sebagai referensi dan sumber informasi untuk memperkuat keputusan yang diambil dan memperbanyak pengetahuan untuk pemecahan masalah yang akan dihadapi. Adapaun teori yang dibahas Ujian Teori, Penerimaan Siswa Baru, Internet, Website, Browser, HTML, PHP, JavaScript, Database, Mysql, Apache web server, Unified Modeling Language (UML), Normalisasi, Metode Pengembangan Sisten, Metode Pengujian Sistem dan Alat bantu pengembangan sistem.

\subsection{Metode Air Terjun}

Model air terjun (waterfall) adalah model satu arah yang dimulai dari tahap persiapan sampai perawatan, dan model inilah yang dipakai oleh penulis dalam menganalisa sistem yang akan dikerjakan (Pressman, 2002).

Metode yang digunakan dalam menganalisis data ini adalah menggunakan metode the Classic Life Cycle atau pada umumnya dikatakan waterfall. Pada metode ini terdapat 5 (lima) tahap untuk mengembangkan suatu perangkat lunak. Kelima tahapan itu tersusun dari atas kebawah, diantaranya Analisis, Design, coding, Testing, dan Maintenance.

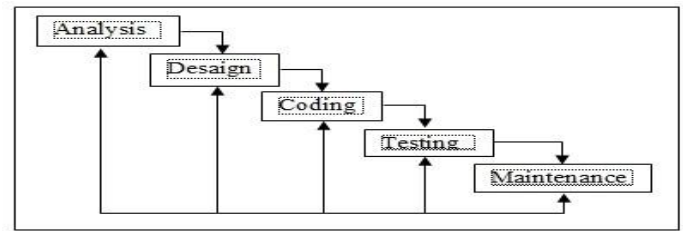

Gambar 1. Metode WaterFall

Berikut ini akan diuraikan tahap-tahap pengembangan perangkat lunak dengan menggunakan metode waterfall, yaitu:

1) Analisis adalah tahapan menganalisa hal-hal yang diperlukan dalam pelaksanaan proyek pembuatan atau pengembangan software. Dalam hal ini analisis yang dilakukan dengan menganalisa data yang akan diinput seperti data peserta, bentuk soal dan laporan hasil ujian peserta yang akan diumumkan.

2) Desaign adalah penterjemahan dari keperluankeperluan yang dianalisis dalam bentuk yang lebih mudah dimengerti oleh pemakai.

3) Coding adalah tahap penterjemah data/pemecahan masalah software yang telah dirancang dalam bahasa 
pemograman yang telah ditentukan. Pada tahap ini bahasa pemograman yang digunakan dalam pembuatan sistem adalah PHP.

4) Testing adalah tahap pengujian terhadap program yang telah dibuat. Pengujian ini dimulai dengan membuat suatu uji kasus untuk setiap fungsi pada ujian teori berbasis web kemudian dilanjutkan pengujian terhadap modul-modul dan terakhir pada tampilan antar muka untuk memastikan tidak ada kesalahan dan semua berjalan dengan baik dan input yang diberikan hasilnya sesuai dengan yang diinginkan.

5) Maintenance adalah perangkat yang telah dibuat dapat mengalami perubahan sesuai permintaan pemakai. Pemeliharaan dapat dipakai jika ada permintaaan penambahan fungsi sesuai dengan keinginan pemakai ataupun adanya pertumbuhan dan perkembangan baik perangkat lunak maupun perangkat keras.

\subsection{Analisis Sistem}

1) Flowchart Sistem Untuk Admin

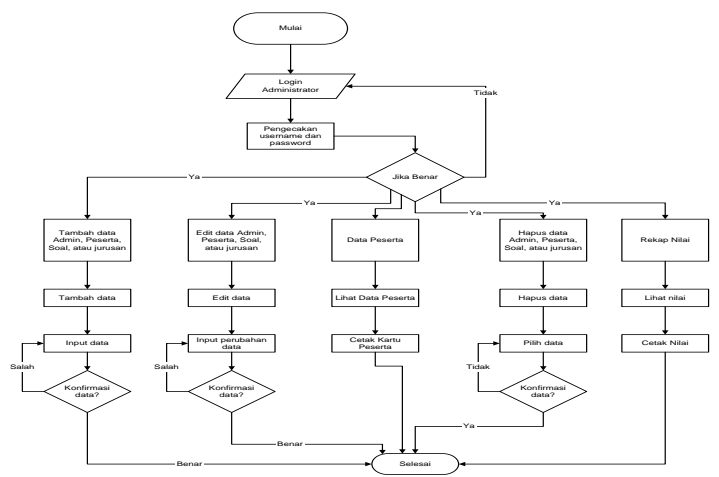

Gambar 2. Flowchart untuk admin

2) Flowchart Sistem Untuk Peserta

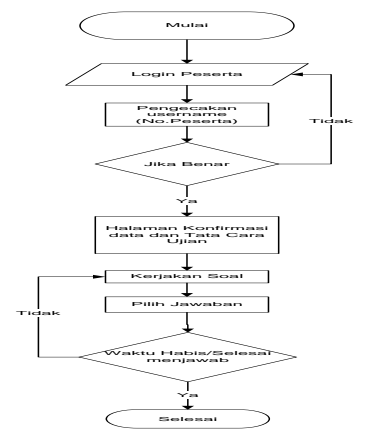

Gambar 3. Flowchart untuk peserta

\subsection{Analisis Dokumen}

Tabel 1. Tabel Analisa Dokumen

\begin{tabular}{|l|l|l|}
\hline No & Nama Dokumen & Deskripsi \\
\hline 1. & Data Soal & $\begin{array}{l}\text { Fungsi : merupakan dokumen } \\
\text { yang berisi tentang data soal-soal } \\
\text { yang akan diujikan }\end{array}$ \\
\hline 2. & Data Peserta & $\begin{array}{l}\text { Fungsi : untuk mengetahui data } \\
\text { peserta yang mengikuti ujian }\end{array}$ \\
\hline 3. & Data Jurusan & Fungsi : untuk mengetahui data \\
\hline
\end{tabular}

\begin{tabular}{|l|l|l|}
\hline & & jurusan yang ada di sekolah \\
\hline 4. & Data User & $\begin{array}{l}\text { Fungsi : untuk mengetahui data } \\
\text { user (dimana user yaitu panitia) } \\
\text { yang melakukan pengelolaan web }\end{array}$ \\
\hline 5. & $\begin{array}{l}\text { Daftar Nilai } \\
\text { Peserta }\end{array}$ & $\begin{array}{l}\text { Fungsi : untuk mengetahui nilai } \\
\text { hasil ujian peserta }\end{array}$ \\
\hline
\end{tabular}

\section{RANCANGAN SISTEM/APLIKASI}

1) Use Case Diagram Yang Berjalan

Use case diagram merupakan pemodelan untuk mendeskripsikan sebuah interaksi antara satu atau lebih aktor di dalam sistem yang sedang berjalan. Use case digunakan untuk mengetahui fungsi apa saja yang ada didalam sebuah sistem dan siapa saja yang berhak menggunakan fungsi-fungsi itu.

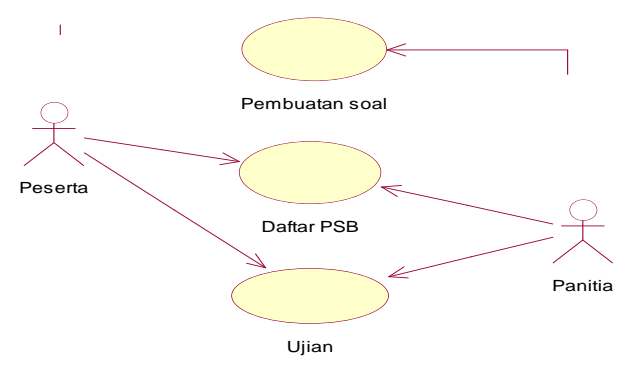

Gambar 4. Use Case Diagram ujian yang berjalan

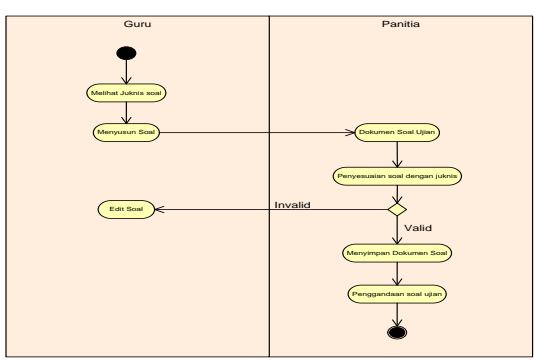

Gambar 5. Activity Diagram Soal

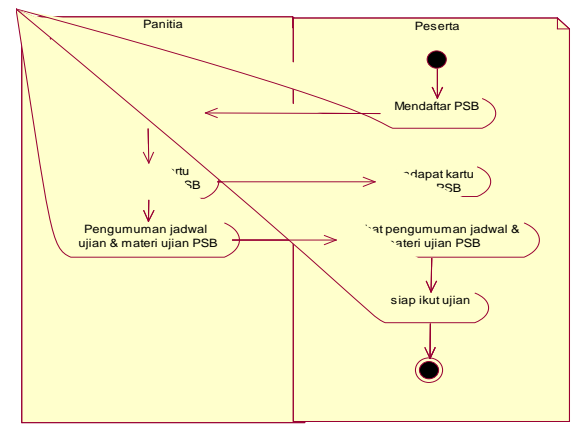

Gambar 6. Activity Diagram Daftar PSB 


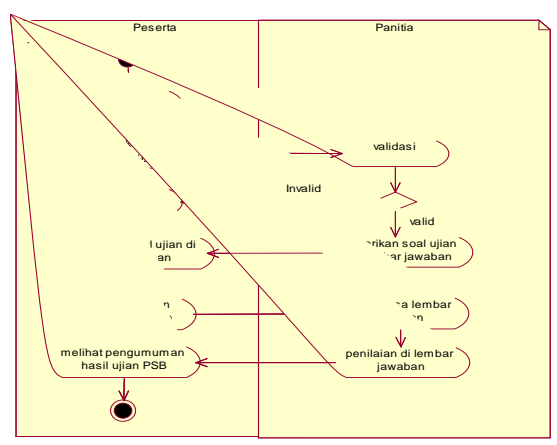

Gambar 7. Activity Diagram Ujian

2) Desain Prosedur Yang Diusulkan

Untuk membuat suatu aplikasi dan membangun satu hasil yang berguna bagi pengguna aplikasi tersebut, maka diperlukan desain untuk rancangan-rancangan prosedur. Bab berikut menjelaskan rancangan prosedur yang diusulkan untuk pembuatan Aplikasi Ujian PSB Online di SMK Bhakti Loa Janan.

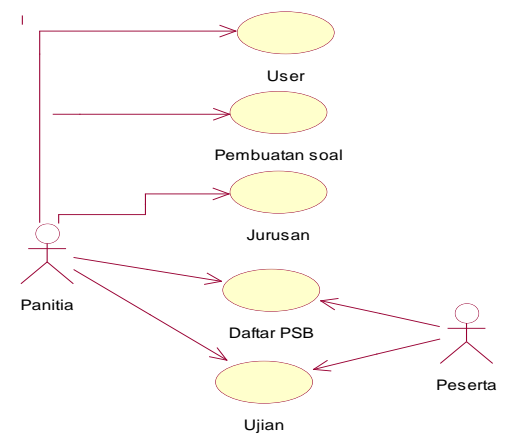

Gambar 8. Use case diagram yang diusulkan

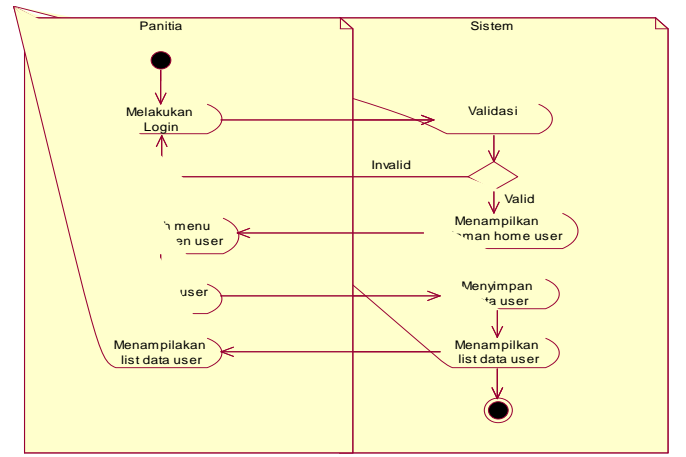

Gambar 9. Activity Diagram User

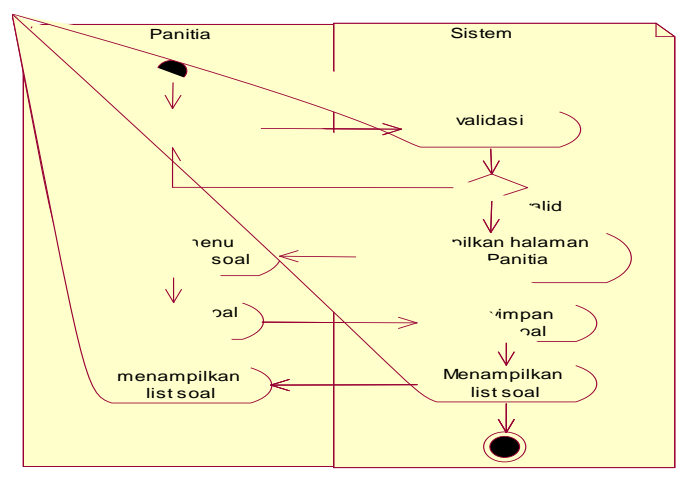

Gambar 10. Activity Diagram Soal

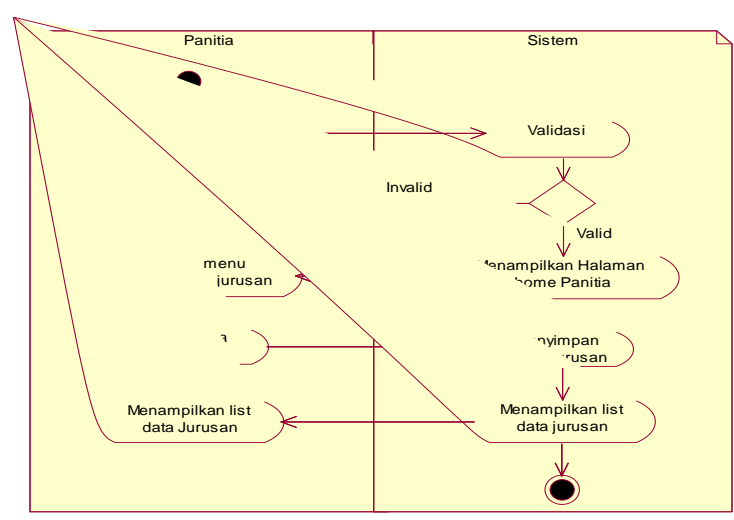

Gambar 11. Activity Diagram Jurusan

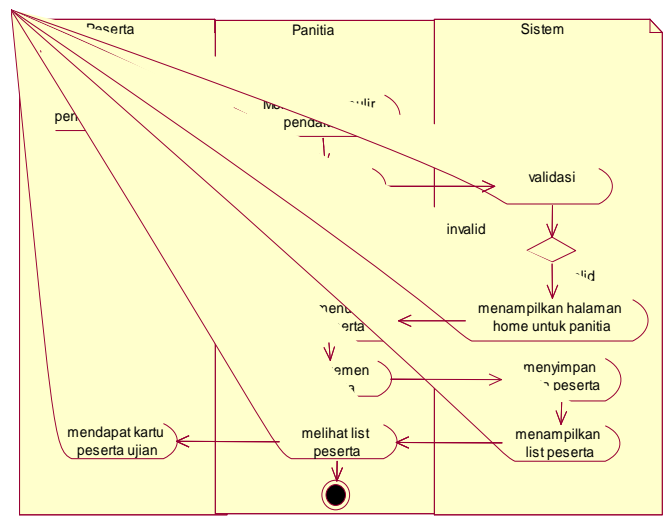

Gambar 12. Activity Diagram Daftar PSB

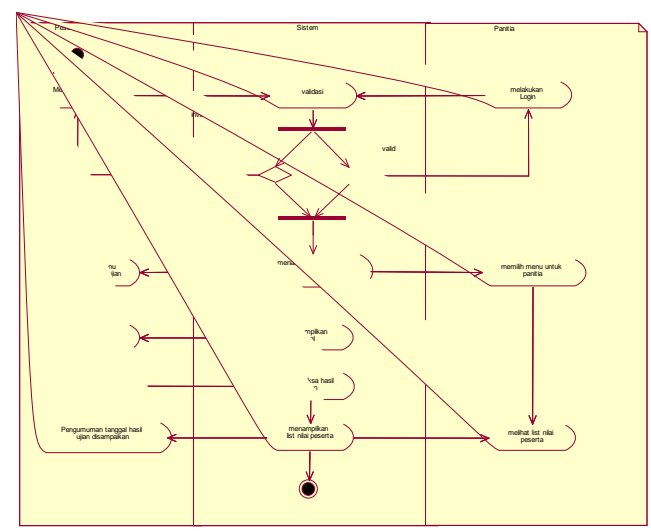

Gambar 13. Activity Diagram Ujian

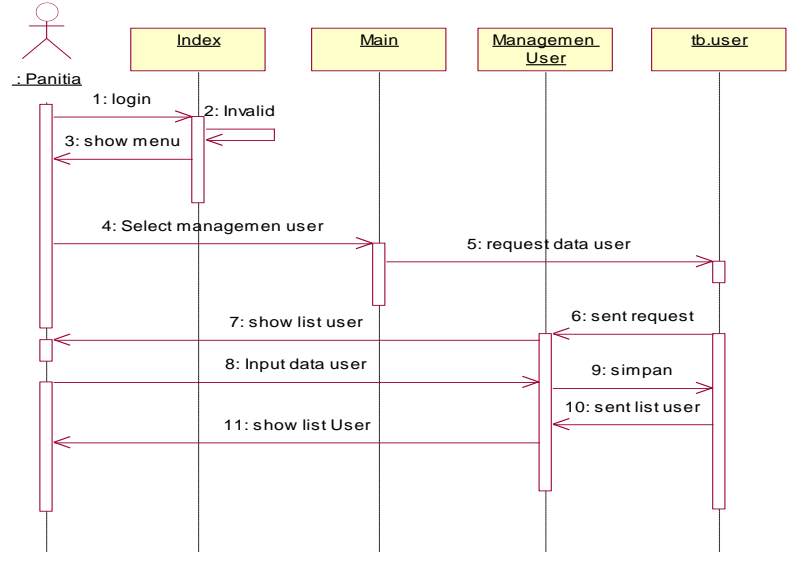

Gambar 14. Diagram Sequence User 


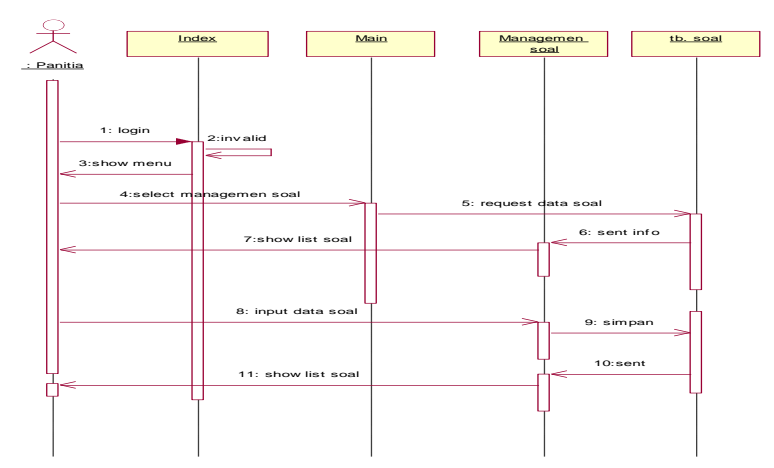

Gambar 15. Diagram Sequence Soal

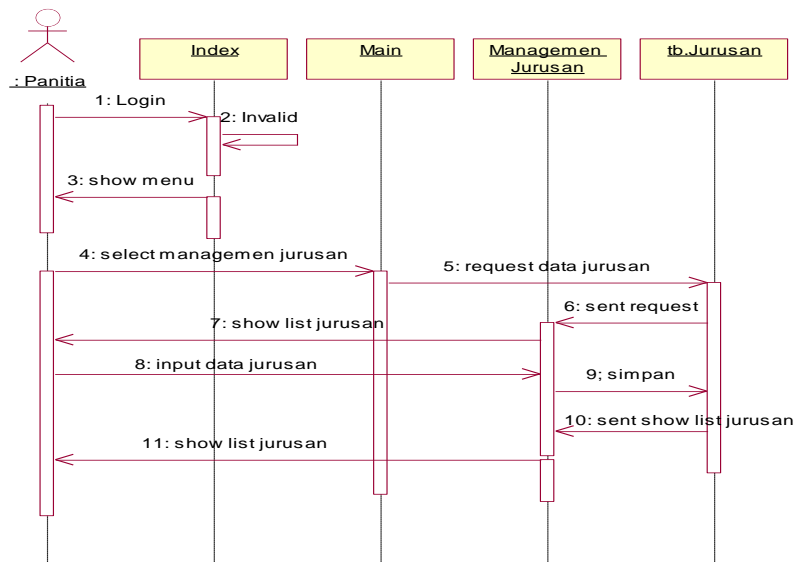

Gambar 16. Diagram Sequence Jurusan

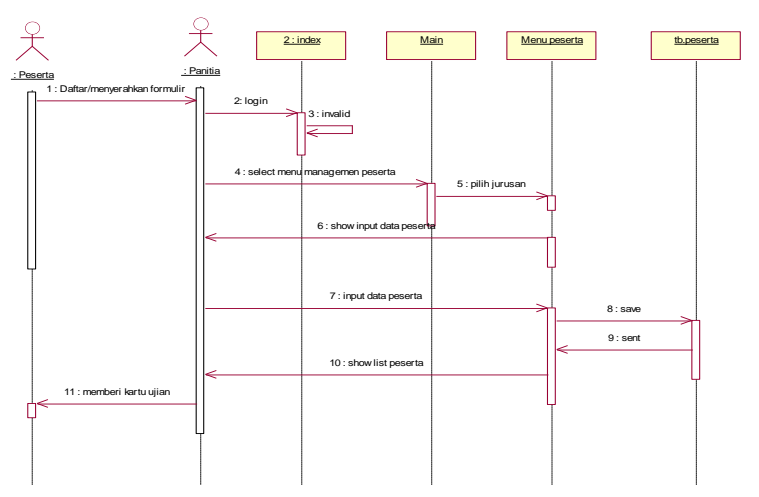

Gambar 17. Diagram Sequence Daftar PSB

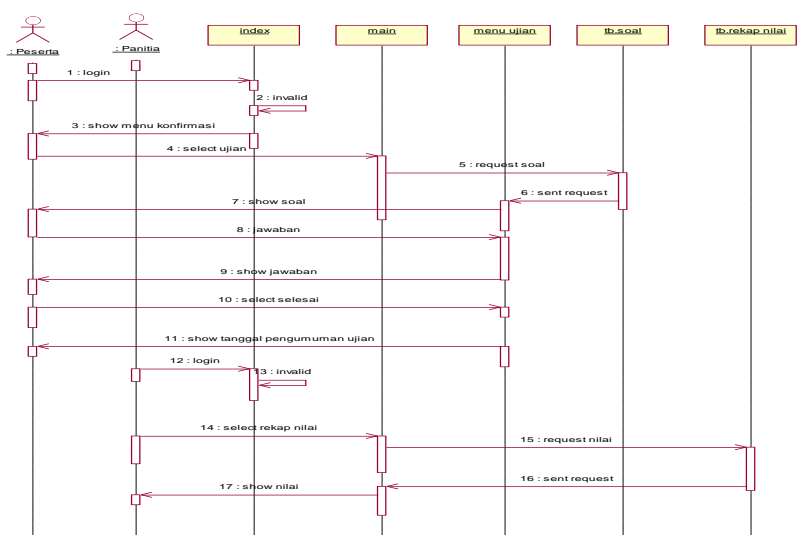

Gambar 18. Diagram Sequence Ujian

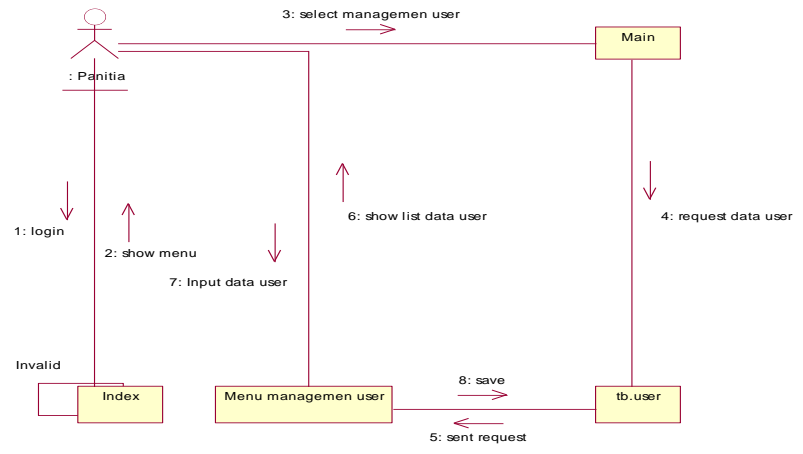

Gambar 19. Diagram collaboration User

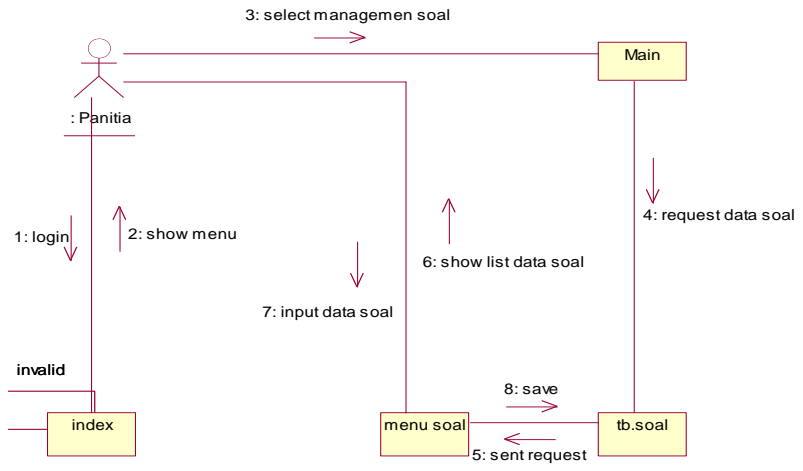

Gambar 20. Diagram collaboration soal

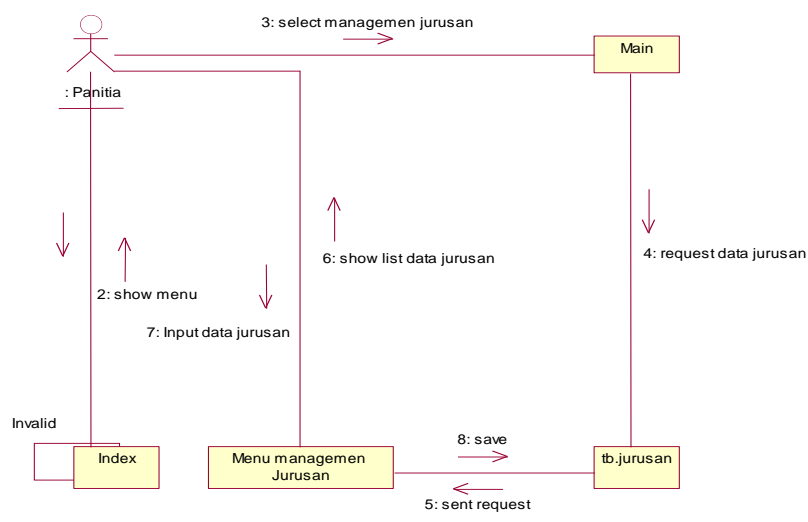

Gambar 21. Diagram collaboration jurusan

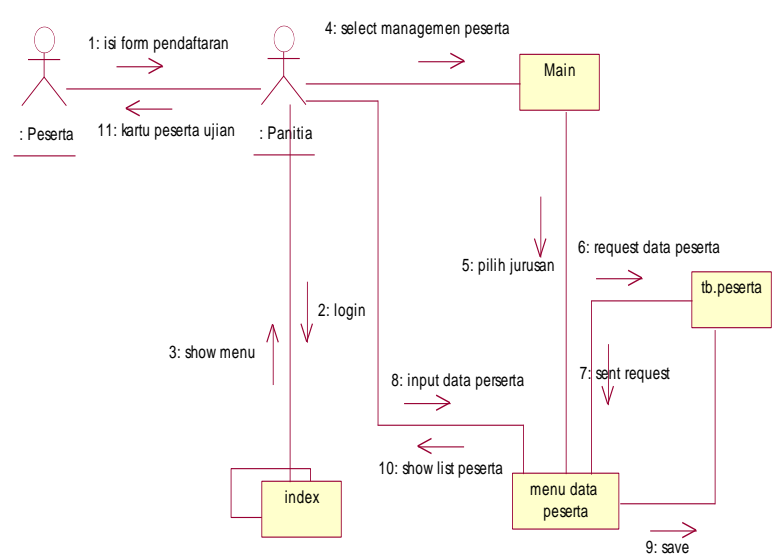

Gambar 22. Diagram collaboration Daftar PSB 


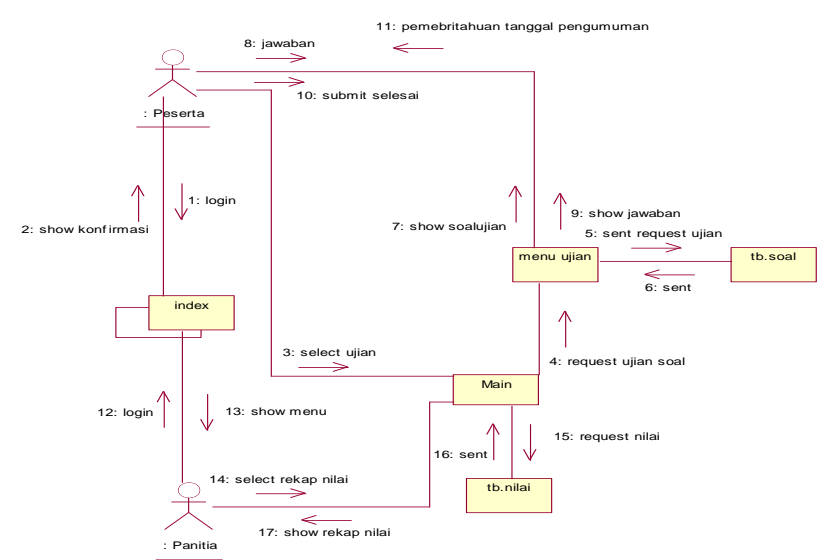

Gambar 23. Diagram collaboration Ujian

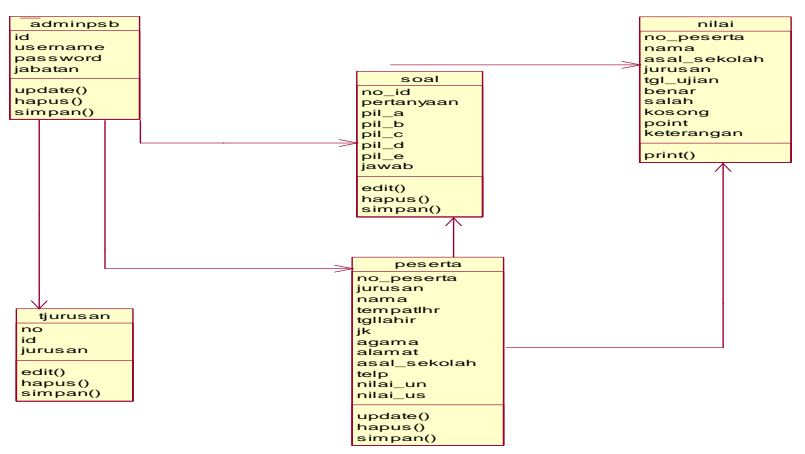

Gambar 24. Class diagram Aplikasi ujian online

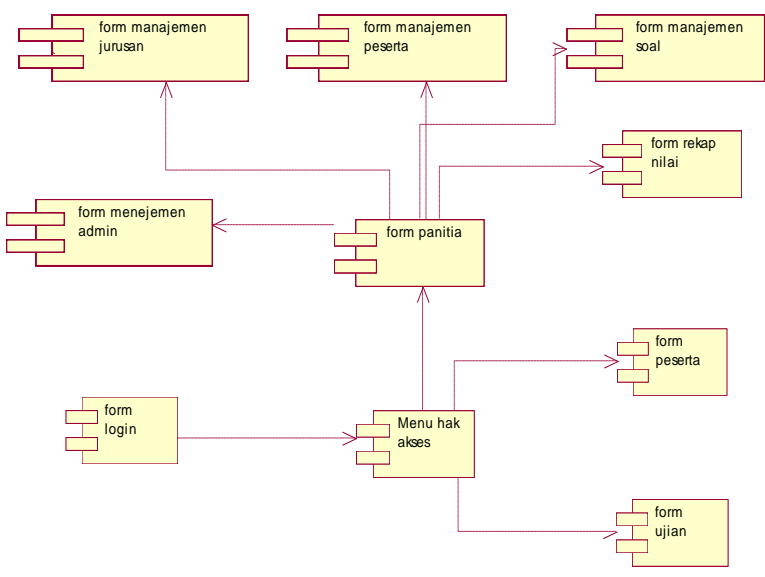

Gambar 25. Component diagram Aplikasi ujian PSB online

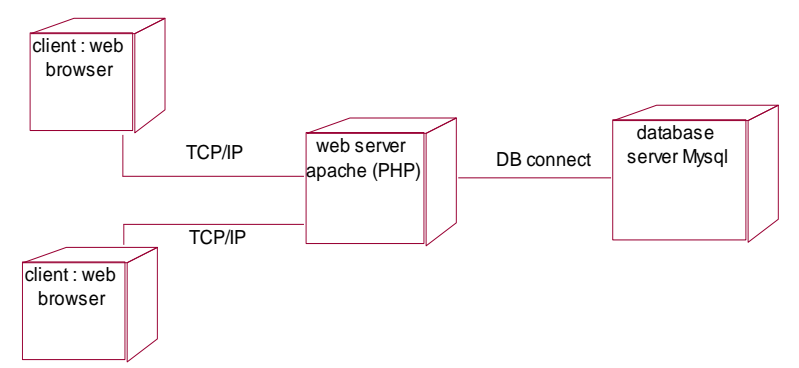

Gambar 26. Deployment diagram Aplikasi ujian PSB online
3) Desain Database

Tabel 2. Tabel adminpsb

\begin{tabular}{|l|l|l|l|}
\hline Field & Tipe & Lebar & Keterangan \\
\hline id & int & 10 & Primary Key \\
username & varchar & 50 & Nama pengguna \\
password & varhar & 8 & Password untuk login \\
jabatan & varchar & 20 & Jabatan pengguna \\
\hline
\end{tabular}

Tabel 3. Tabel Peserta

\begin{tabular}{|c|c|c|c|}
\hline Field & Tipe & Lebar & Keterangan \\
\hline $\begin{array}{l}\text { no_peserta } \\
\text { jurusan } \\
\text { nama } \\
\text { tempatlhr } \\
\text { tgllhr } \\
\text { jk } \\
\text { agama } \\
\text { alamat } \\
\text { asal_sekolah } \\
\text { telp } \\
\text { nilai_un } \\
\text { nilai_us }\end{array}$ & $\begin{array}{l}\text { Varchar } \\
\text { varchar } \\
\text { varchar } \\
\text { varchar } \\
\text { date } \\
\text { char } \\
\text { varchar } \\
\text { text } \\
\text { varchar } \\
\text { int } \\
\text { varchar } \\
\text { varchar }\end{array}$ & $\begin{array}{l}7 \\
35 \\
50 \\
50 \\
\\
1 \\
35 \\
\\
50 \\
15 \\
5 \\
5\end{array}$ & $\begin{array}{l}\text { Primary Key } \\
\text { Jurusan yang dipilih } \\
\text { peserta } \\
\text { Nama lengkap peserta } \\
\text { Tempat lahir peserta } \\
\text { Tanggal lahir peserta } \\
\text { Jenis kelamin peserta } \\
\text { Agama peserta } \\
\text { Alamat peserta } \\
\text { Asal sekolah peserta } \\
\text { (SMP) } \\
\text { No. telepon peserta } \\
\text { Nilai ujian nasional } \\
\text { peserta } \\
\text { Nilai ujian sekolah } \\
\text { peserta }\end{array}$ \\
\hline
\end{tabular}

Tabel 4. Tabel Jurusan

\begin{tabular}{|l|l|l|l|}
\hline Field & Tipe & Lebar & Keterangan \\
\hline id & int & 4 & Primary Key, Kode jurusan \\
jurusan & text & 35 & Jurusan yang ada di sekolah \\
\hline
\end{tabular}

\section{Tabel 5.Tabel Soal}

\begin{tabular}{|c|c|c|c|}
\hline Field & Tipe & Lebar & Keterangan \\
\hline $\begin{array}{l}\text { no_id } \\
\text { pertanyaan } \\
\text { pil_a } \\
\text { pil_b } \\
\text { pil_c } \\
\text { pil_d } \\
\text { pil_e } \\
\text { jawab }\end{array}$ & $\begin{array}{l}\text { Int } \\
\text { text } \\
\text { text } \\
\text { text } \\
\text { text } \\
\text { text } \\
\text { text } \\
\text { text }\end{array}$ & 4 & $\begin{array}{l}\text { Primary Key, auto } \\
\text { increament } \\
\text { Isi pertanyaan } \\
\text { Isi jawaban A } \\
\text { Isi jawaban B } \\
\text { Isi jawaban C } \\
\text { Isi jawaban D } \\
\text { Isi jawaban E } \\
\text { Jawaban dari soal }\end{array}$ \\
\hline
\end{tabular}

Tabel 6. Tabel Rekap Nilai

\begin{tabular}{|l|l|l|l|}
\hline Field & Tipe & Lebar & Keterangan \\
\hline no_peserta & Int & 7 & Primary Key \\
nama & varchar & 50 & Nama peserta \\
asal_sekolah & varchar & 50 & Asal sekolah (SMP) \\
jurusan & varchar & 35 & Jurusan yang dipilih \\
benar & varchar & 3 & Jumlah jawaban yang benar \\
salah & varchar & 3 & Jumlah jawaban yang salah \\
kosong & varchar & 3 & Jumlah jawaban yang kosong \\
point & varchar & 3 & Jumlah nilai \\
\hline
\end{tabular}

\section{Implementasi}

Untuk dapat dimengerti oleh mesin, dalam hal ini adalah komputer, maka desain harus diubah bentuknya menjadi bentuk yang dapat dimengerti oleh mesin, yaitu ke dalam bahasa pemrograman melalui proses coding. Tahap ini merupakan 
implementasi dari tahap design sebelumnya yang secara teknis nantinya dikerjakan oleh programmer. Tujuan coding yang menjadi implementasi ini adalah untuk menjelaskan tentang manual modul kepada semua user yang akan menggunakan aplikasi. Sehingga user tersebut dapat merespon apa yang ditampilkan diaplikasi dan memberikan masukan kepada pembuat aplikasi untuk melakukan perbaikan agar aplikasi lebih baik lagi.

\section{1) Antar Muka}

Dari rancangan-rancangan antar muka dibuatlah coding yang akan diimplementasikan menjadi sebuah tampilan antar muka pada web yang dibuat. Antar muka Aplikasi Ujian Online di SMK Bhakti Loa Janan ini terdiri dari beberapa tampilan diantaranya, login, menu peserta, menu admin, managemen admin, managemen peserta, managemen soal, jurusan, rekap nilai, dan menu ujian online untuk peserta. Tampilan ini merupakan tampilan awal atau home dari aplikasi web ini. Dimana halaman ini dapat menú login yang diakses oleh peserta karena di tampilan ini terdapat form login peserta agar bisa masuk dan mengerjakan soal.

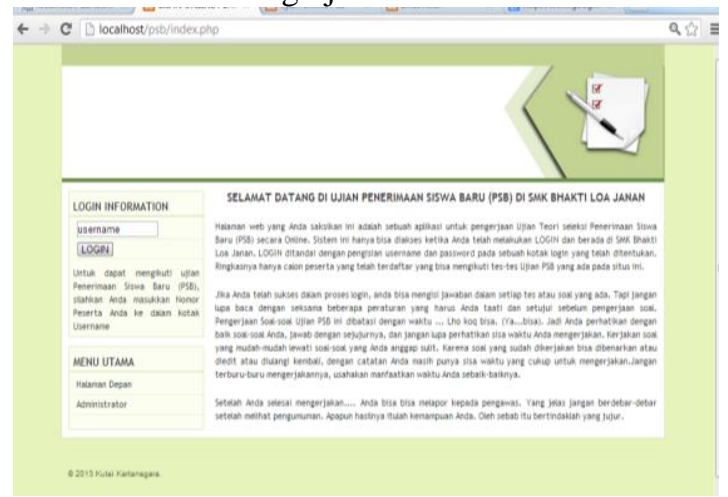

Gambar 27. Tampilan form login

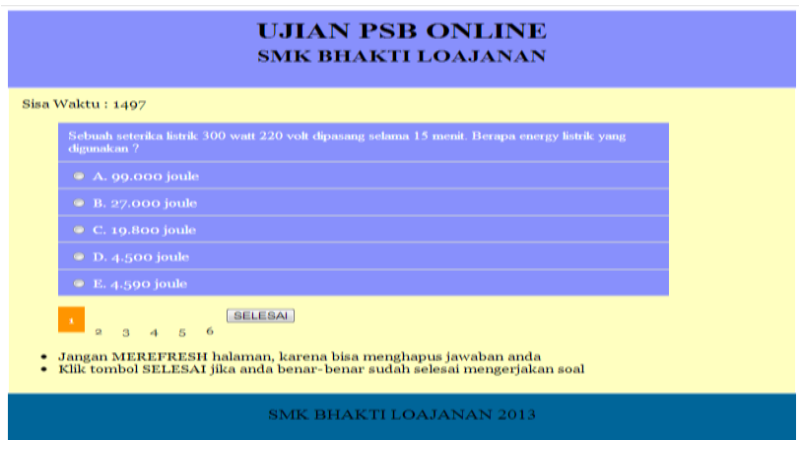

Gambar 28 Tampilan Ujian Online

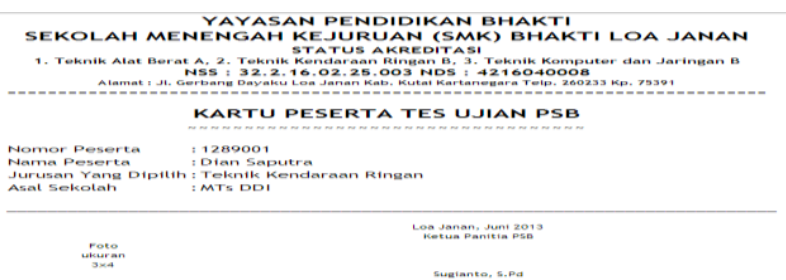

Gambar 29 Tampilan Cetak Kartu Peserta Ujian

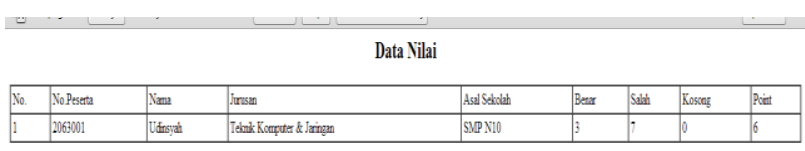

Gambar 30. Tampilan Menu nilai ujian peserta

\section{Tahap Pengujian}

Pengujian merupakan bagian penting dalam siklus pembuatan atau pengembangan perangkat lunak. Pengujian dilakukan untuk menjamin kualitas dan juga mengetahui kelemahan dari perangkat lunak. Tujuan dari pengujian perangkat lunak ini adalah untuk menjamin bahwa perangkat lunak yang dibangun memiliki kualitas dan dapat diandalkan. Pengujian perangkat lunak ini menggunakan metode pengujian Black Box dan Beta Testing. Pengujian Black Box digunakan untuk menguji fungsi-fungsi khusus dari aplikasi perangkat lunak yang dirancang. Sedangkan pengujian Beta Testing digunakan dengan cara memberikan kuesioner kepada responden untuk menilai penggunaan ujian online tersebut.

1) Pengujian Black Box

Rencana Pengujian Pengujian perangkat lunak Sistem Aplikasi Ujian online Di SMK Bhakti Loa Janan dengan metode black box. Pengujian black box berfokus pada persyaratan fungsional perangkat lunak yang dibuat

2) Pengujian Beta (Beta Testing)

Pengujian beta testing dalam hal ini dilakukan dengan cara memberikan kuesioner yang dilakukan kepada 10 responden yang akan menjawab sejumlah pertanyaan yang diajukan dan responden adalah siswa-siswi kelas $\mathrm{X}$ yang diambil secara acak dari 3 jurusan yang ada di SMK Bhakti Loa Janan. Adapun indikator kuisioner yang digunakan pertanyaan pengujian yang berdasarkan kriteria-kriteria website yang baik, pertanyaan-pertanyaan pengujian.

\section{KESIMPULAN}

Kesimpulan yang dapat ditarik dari permasalahan perancangan ujian Penerimaan Siswa Baru berbasis web ini adalah sebagai berikut:

1) Telah dibuat aplikasi ujian teori Penerimaan Siswa Baru di SMK Bhakti Loa Janan berbasis intranet dengan bahasa pemrograman PHP (Pre Hypertext Processor).

2) Aplikasi ini memiliki beberapa kelebihan dibandingkan dengan sistem lama yang konvensional, berikut beberapa kelebihan dari aplikasi ujian ini adalah:

a) Mudah di akses dengan tampilan GUI (graphic user interface) yang user friendly.

b) Proses ujian bisa lebih cepat dan efisien karena tidak memerlukan media alat tulis seperti ujian konvensional.

c) Sistem menampilkan soal random untuk mempersempit kecurangan dalam proses ujian dan merupakan pengembangan sistem sebelumnya.

d) Memudahkan panitia karena tidak perlu melakukan pengecekan /koreksi jawaban ujian. 
e) Peserta tidak perlu menanyakan soal karena tulisan atau gambar yang tidak jelas.

f) Pengadaan aplikasi ini tidak memerlukan biaya mahal.

\section{SARAN}

Untuk pengembangan lebih lanjut dari aplikasi web ini, ada beberapa saran yang dapat diberikan, antara lain :

1) Ujian online ini bukan digunakan hanya ujian PSB tetapi juga bisa digunakan untuk siswa-siswi kelas X, XI, dan XII semua jurusan di SMK Bhakti serta di upload ke internet atau domain public agar dapat diakses dimana saja dan kapan saja, sebagai latihan bagi siswa-siswa dalam mengevaluasi kemampuan mereka.

2) Ditambahkannya fitur download soal dan materi, agar setelah selesai ujian siswa dapat mengunduh soal ke dalam format PDF atau file dokumen lainnya.

3) Untuk ujian skala lokal atau masih dalam satu area network dapat dikembangkan dengan menggunakan remote desktop agar pengawas bisa langsung mengawasi proses ujian secara langsung dari layar monitor pengawas.

\section{DAFTAR PUSTAKA}

Arbie, 2003. Manajemen Database dengan MySQL. Yogyakarta : Andi.

Divisi Penelitian dan Pengembangan MADCOMS. 2004. Aplikasi Program PHP \& MySQL. Madiun : Penerbit Andi.

Desrizal, 2010. Panduan Lengkap PHP ajax jQuery, Bandung.

Fathansyah, 2004. Basis Data, Informatika : Bandung.

Fowler, Martine, 2005. UML Distilled Edisi 3. Yogyakarta: Andi.

Hakim, Lukmanul. 2008. Membongkar Trik Rahasia Para Master Php. Yogyakarta : Lokomedia.

Irwanto,Djon, 2006. Perancangan Objec Oriented Software dengan UML. Yogyakarta. Andi.

Jogiyanto. H.M, 2005. Analisa dan Sistem Informasi: Pendekatan Terstruktur Teori dan Praktek Aplikasi Bisnis, Yogyakarta : Andi Offset.

Kadir, Abdul. 2002. Pemgrograman Web Mencakup HTML, CSS, JAVASCRIPT, \& PHP. Yogyakarta : Penerbit Andi Yogyakarta.

Kadir, Abdul. 2008. Belajar Database menggunakan MySQL. Yogyakarta: Penerbit Andi
Madcoms, 2008. Teknik Mudah Membangun Website dengan HTML, PHP , dan MYSQL. Madiun : Andi.

Nugroho, Bunafit 2004. PHP dan MySQL, dengan Editor Dreamweaver $M X$, Yogyakarta : Penerbit Andi

Nugroho, Bunafit. 2007. Trik dan Rahasia Membuat Aplikasi Web dengan PHP. Yogyakarta : Gava Media.

Peranginangin, Kasiman 2006. Aplikasi WEB dengan PHP dan MySQL, Yogyakarta : Andi Offset.

Prasetio, Adhi. 2010. Cara Mudah Membuat Desain Web untuk Pemula. Jakarta : Medikita.

Prasetya, Andreas Hery, 2010. Cepat Kuasai PHP dan MySql, Yogyakarta: Andi.

Pressman, Roger S. (2010). Software Engineering : A Practicioner's Approach, 7th Edition. McGrawHill Inc., New York.

Purbo, Ono W dan Sembiring, Akhmad D. 2004. Buku Pintar Internet Apache Web Server. Jakarta : Elex Media Kamputindo.

Sakur, Standy B, 2004, "Aplikasi Web Database Dengan Dreamweaver $M X$ " Yogyakarta : Penerbit Andi.

Sugiyono. 2009. Metode Penelitian Pendidikan Pendekatan Kuantitatif, kualitatif dan $R \& D$. Bandung : Alfabeta. 